\title{
PROCESSOS TECNOLÓGICOS, EDUCAÇÃO E ARTE: REFLEXÕES SOBRE A CRIAÇÃO COM ENFOQUE PARA A EJA - EDUCAÇÃO DE JOVENS E ADULTOS
}

\author{
Miriam Araújo Nascimento ${ }^{1}$
}

\begin{abstract}
Resumo
O estudo aqui apresentado tem como proposta refletir sobre a criação com enfoque para a articulação entre Processos Tecnológicos, Educação e Arte. Como parte da pesquisa de contextualização conceitual, base epistemológica que estamos desenvolvendo, discutimos a docência priorizando o saber emergente, desenvolvido no entrelaçamento entre ensino-pesquisa-extensão, essencial para enfatizar a questão de que a produção de sentidos-conhecimentos é recorrente dos processos de vida. Assim, este estudo tem como objetivo apresentar reflexões sobre o percurso dos sujeitos e sobre o potencial de criatividade destes, tendo em vista que é no percurso que acontece a criação de conhecimentos e de obras de arte e a própria composição do currículo sempre em processos criativos. Sendo que essas criações, seja na EJA - Educação de Jovens e Adultos, seja no ensino regular, constituem-se continuamente a partir das relações históricosocial, possuem caráter contextual, local, emergente, acontecimental e relacional. E, por isso mesmo, essas criações também provêm da relação do sujeito com suas experiências, com sua historicidade, com sua dinâmica interna e com a própria dinâmica do viver. A proposta deste estudo, todavia, evidencia que o ser humano em si mesmo teckné, se desenvolve num contexto de diálogo, transformação e criação, no qual cada um tem a possibilidade de experienciar, criar e ao mesmo tempo ampliar potencialidades geradas nas relações.
\end{abstract}

Palavras-chave: Docência. Arte. Processos Tecnológicos. Educação de Jovens e Adultos.

\section{TECHNOLOGICAL PROCESSES, EDUCATION AND ART: REFLECTIONS ON THE ESTABLISHMENT WITH FOCUS FOR EJA - YOUTH AND ADULT EDUCATION}

\begin{abstract}
The study presented here is to reflect on the proposed creation with a focus on the articulation of Technological Processes, Education and Art. As part of the research context of conceptual, epistemological basis we are developing, we discuss teaching prioritizing emerging knowledge developed in the intersection between teaching-research-extension, essential to emphasize the point that the production of meanings and knowledge of the applicant's processes life. Thus, this study aims to present reflections on the route of the subjects and the potential for creativity, bearing in mind that the journey is what happens to knowledge creation and works of art and the very composition of the curriculum always creative processes. Since these creations, whether in the EJA - Youth and adults, whether in mainstream education, are formed continuously from the socio-historical relations have contextual, local, emerging, and evental relational character. And, therefore, these creations also arise from the relation of the subject with their experiences, their historicity, with their internal dynamics and the dynamics of living. This study, however, shows that the human being itself teckné, develops in a context of dialogue, transformation and creation, in which everyone has the opportunity to experience, create and simultaneously expand potential generated in relations.
\end{abstract}

Keywords: Teaching. Art. Technological Processes. Education Youth and adults.

\footnotetext{
${ }^{1}$ Estudante do Mestrado Profissional em Educação de Jovens e Adultos - Mpeja - Universidade do Estado da Bahia (Uneb). Bolsista Fapesb - Fundação de Amparo à Pesquisa do Estado da Bahia. Especialista em Currículo de Formação Científica Tecnológica e Cultural - Universidade do Estado da Bahia (Uneb). Especialista em História Social e Econômica do Brasil - Faculdade São Bento da Bahia (Fsbb). Licenciada em Desenho e Plástica - Escola de Belas Artes - Universidade Federal da Bahia (Eba-Ufba). E-Mail: Miriamufba@ Yahoo.com.Br
} 


\section{Introdução}

A educação contemporânea no contexto de transição de paradigmas dominante para emergente convida docentes e discentes a estarem imersos em suas realidades, a fim de desenvolverem juntos conhecimentos novos que tenham como base o percurso individual do sujeito ampliado no entrelaçamento ou imbricamento entre ensino-pesquisa-extensão. De acordo com Cunha (1998, p. 24), Paradigma Dominante refere-se à Educação focada na transmissão-recepção de conhecimentos; e Paradigma Emergente - modo de conceber o conhecimento como espaço conceitual, no qual os alunos e professores constroem um saber novo, produto sempre contraditório de processos sociais, históricos, culturais e psicológicos.

A atividade educativa desenvolvida na "indissociabilidade" (CUNHA, 1998, p.10) dessa base provoca reflexões, compreensões, interpretações que gerarão melhorias para as realidades vividas, a criação de novos conhecimentos e de obras de arte, alterações necessárias e, a elaboração consciente, crítica e criativa de outras realidades. E mais ainda, esta base propicia articular açãoreflexão-ação, trilogia considerada por Pereira e Pereira (2011 p. 6) o "[...] instrumental mais poderoso que se pode proporcionar à prática docente de um professor”.

Neste trabalho, como parte da pesquisa de contextualização conceitual (base) epistemológica que estamos desenvolvendo, adotamos como metodologia estudos bibliográficos, tendo como estratégia: observação em sala de aula, e pesquisas em textos e sites. Discutimos a Docência em sua relação com Processos Tecnológicos e com a Arte, ressaltando que é no percurso do sujeito que se manifestam as criações. Nas reflexões aqui apresentadas procuramos evidenciar que o homem em si é um ser subjetivo, comunitário, crítico, criativo e histórico. E, destacamos de forma crítica que cada estudante da Educação de Jovens e Adultos pode ser considerado um sujeito criativo. Este cria conhecimentos a fim de gerar sentidos e significados para o seu viver.

Assim, o estudo aqui apresentado tem como objeto de estudo apresentar reflexões sobre o percurso do sujeito, tendo em vista que é no percurso que acontece a produção de conhecimento e a própria composição do currículo dos sujeitos sempre em processos criativos. E, além disso, as reflexões, registros e criações de conhecimentos e de obras de arte constituem-se continuamente na própria dinâmica do viver entrelaçada à experiência e dinâmica interna de cada um.

Essas reflexões tecem-se sob a perspectiva de interlocutores como Cunha e Paulo Freire (Docência/Educação), Dantas e Barcelos (Educação de Jovens e Adultos), Domingues, Lima Jr. e Hetkowski (Processos Tecnológicos), e Ostrower e Zambone (Arte). Paulo Freire conceitua a Educação entrelaçada às vivências de cada sujeito; Tânia Regina Dantas apresenta reflexões sobre a Educação de Jovens e Adultos; Valdo Barcelos reflete sobre a criação de conhecimentos e o 
currículo na Educação de Jovens e Adultos. Silvio Zambone caracteriza a Arte elencando suas interrelações com outros conhecimentos; Domingues, Hetkowski e Lima Jr. destacam a Educação e seus entrelaçamentos com os processos tecnológicos.

Neste estudo tomamos as TIC (Tecnologias da Informação e Comunicação) segundo a abordagem de Lima Jr. (2009, p. 28) “[...] enquanto processo e contexto de comunicação social, são espaços abertos [...]", e tecnologia, segundo o conceito grego de teckné - criação e transformação não apenas manipulação. Este autor (2005, p. 16) apresenta que: “o processo tecnológico, de acordo com a matriz grega, relaciona e articula indissociavelmente o ser humano e os utensílios e recursos materiais ou imateriais por ele criados, de modo que não há como concebê-los como realidades independentes, autônomas". O ideal de acordo com esta perspectiva, é que cada sujeito, conscientemente, funcione tecnologicamente: sendo "[...] criativo na presença ou na ausência dos suportes de comunicação e informação [...]” (LIMA JR., 2009, p. 19), pois cada um ser já imbricado com suas criações é no dizer de Lima Jr. (2005): “tecnologia inteligente”.

Quanto a Educação acordamos com Freire (1990, p. 7), é uma relação dialética dos seres humanos com o mundo e com a linguagem e ação transformadora, a parte de um processo pelo qual alguém se torna autocrítico a respeito da natureza, historicamente, construída a partir de sua própria experiência. E, Cunha (1998, p. 53) apresenta que: “[...] as experiências de vida e o ambiente sócio cultural são componentes-chave na explicação do desempenho atual do professor, quer na categoria da reprodução quer na da contradição. O conjunto de valores e crenças que dão escopo à performance dos docentes são frutos de sua história e suas experiências de vida dão contornos ao seu desempenho".

E, a Arte dizendo com Zambone (2006, p. 23): “[...] é uma forma de conhecimento que nos capacita a um entendimento mais complexo, e de certa forma, mais profundo das coisas". De acordo com este autor, a arte transmite mensagens de natureza ampla e subjetiva. Sendo que, "o lógico e o sensível complementam-se, e essas duas formas não são independentes e dissociadas" (ibidem, p. 23). Mas, “[...] na realidade, diferentes tipos de 'racionalidade' interagem, por vezes confundem-se, auxiliam-se e complementam-se na produção e na recepção das mensagens expressivas e intrínsecas contidas nas obras de arte" (ZAMBONE, 2006, p. 9).

Ainda, para Ostrower (1987, p. 27; 1990, p. 218) a arte é potência ampla e aberta, pois tem em si a criação e a criatividade e apresenta em sua gênese o potencial criador inerente ao homem. Sendo assim, a arte contribui para que cada indivíduo a partir de sua subjetividade fomente seu processo formativo. A autora destaca que "[...] a criatividade está no potencial de cada um - e a 
criação já é escolha de cada um" (OSTROWER, 1990, p. 218). E, no ato de criar integra-se a criação e a criatividade. Sendo que a criatividade é, inerente ao homem, artista por profissão ou não.

As reflexões contidas neste estudo sobre a articulação entre Arte, Educação e Processos Tecnológicos sugerem, todavia, que o ser humano se desenvolve num contexto de diálogo, de transformação e de criação, no qual cada um tem a possibilidade de vivenciar suas experiências historicamente constituídas e, ao mesmo tempo ampliar suas potencialidades nas relações. Cada sujeito, desse modo, dá sentido a cada ação vivenciada e potencializa novas criações e, além disso, contribui para que todos se comuniquem potencializando significados.

O plano do artigo aqui apresentado segue os seguintes tópicos: (1) o contexto educativo e artístico na contemporaneidade; (2) Educação de Jovens e Adultos na contemporaneidade: reflexões, desafios e possibilidades; (3) docência e arte: reflexões, registros e criações em processos criativos - percurso do sujeito e (4) a importância da Arte na Educação de Jovens e Adultos.

Acreditamos que, cada um, com a possibilidade de criar, configura seu próprio percurso desenvolvendo sua autonomia, a busca de respostas originais, a criatividade, a possibilidade de engendrar qualidades ainda desconhecidas, e, essencialmente de constituir realidades transitórias, contextualizadas, virtuais. Acreditamos, neste sentido, que esta pesquisa será de grande proveito, pois, apresenta reflexões sobre a criação com enfoque para o entrelaçamento arte, educação e processos tecnológicos. Nosso intuito, todavia, centra-se em provocar novas reflexões e futuras pesquisas sobre os tópicos apresentados.

\section{O contexto educativo e artístisco na contemporaneidade}

A questão da percepção que os professores têm sobre o conhecimento é a base da proposta inovadora.

(CUNHA, 1998, p. 67)

O final do século XX e início do século XXI são considerados um período de transição de paradigmas - dominante para emergente. Cunha (1998) em seus estudos demonstra que a Docência, nesta época, deve deixar fruir a concepção de que os conhecimentos são constituídos na dinâmica da vida, sendo, portanto, um processo em permanente reconstrução. Neste sentido, o perfil do docente deve ser gerado de maneira a possibilitar o envolvimento, a produção e a ampliação de dimensões inerentes aos sujeitos, ou seja, ao desenvolvimento cognitivo, interpretativo e criativo de cada um.

No entanto, essa possibilidade se tornará eficaz, se ocorrer um rompimento com o ensino tradicional - educação focada apenas na transmissão-recepção de conhecimentos -, e dar-se abertura para o engajamento/participação tanto do professor como do aluno. O ensino, portanto, 
deve está fundamentado no compartilhamento, na produção, e na construção consciente e prazerosa de conhecimentos. Como relata Cunha (1998, p. 93):

Não se trata, apenas de ideologizar o discurso de maneira inconsequente e banal. Trata-se, sim, de viver a própria concepção de mundo junto com seus alunos, mantendo a liberdade de cada um construir suas próprias convicções dando-lhes, entretanto, elementos para isso. Fundamentalmente trata-se de conceber o ensinar e o aprender no conjunto das práticas sociais humanas e inseri-las nas tramas contextuais do tempo que as contornam.

É preciso, sobretudo, entender que o conhecimento constitui-se em contextos interativos e decorre das inquietações do contexto social. Não há como constituir um conhecimento novo sem que este provenha das expectativas e necessidades dos contextos sócio-culturais vivenciados pelos sujeitos e, da interação e convivialidade entre esses sujeitos. Este, todavia, é um dos grandes desafios da docência na atualidade: desenvolver a atividade educativa totalmente entrelaçada com o contexto vivencial de seus alunos.

Essa compreensão certamente possibilitará ao docente imergir-se no paradigma emergente da educação contemporânea, criar conhecimentos e desenvolver aulas criativas, que permitam o entrelaçamento "indissociável” entre ensino, pesquisa e extensão (CUNHA, 1998, p. 10). A prática docente gerada nesses termos permitirá/possibilitará a formação contínua de sujeitos - professores e alunos - reflexivos, críticos, autônomos, criativos e solidários, seja na EJA - Educação de Jovens e adultos, seja no ensino regular.

É preciso ter em vista também que, confrontações e conflitos gerados no entrelaçamento ensino, pesquisa e extensão - enriquecem consideravelmente essa emergente forma de produção de conhecimentos. Pois, articula a singularidade premente a cada indivíduo e, ao próprio contexto cultural-tecnológico de cada sujeito, com a coletividade e as necessidades inerentes ao contexto sócio-cultural dessa coletividade. Os sujeitos, neste sentido, são ativos participantes, pois estão sempre indo ao encontro de, produzindo e propondo alternativas criativas.

No que se refere à Arte, especialmente a arte baiana, chamada de contemporânea, Anselmo (2003) relata que foi por volta dos anos 80 do século XX que a arte baiana começou mais fortemente a aparecer. Neste período os artistas começaram a trabalhar com maior liberdade de criação, embora antes deste período, muitos se dedicassem à formulação de uma arte formativa impregnada das vivências de cada artista. Nos anos 80, de acordo com Anselmo (2003, p. 109): “a produção artística ficou voltada para a linha da formatividade, linha esta proveniente do construtivismo".

Diz-se Construtivismo como explica Stangos (1991, p. 116): "o movimento de arte moderna que esteve intimamente ligado a um organismo comunista revolucionário". O 
construtivismo era a expressão de uma convicção profundamente motivada de que o artista podia contribuir para suprir as necessidades físicas e intelectuais da sociedade como um todo, relacionando-se diretamente com a produção de máquinas, com a engenharia, arquitetura e com os meios gráficos e fotográficos de comunicação. A ideia do construtivismo era captar a verdade do mundo físico. O construtivismo foi um movimento fisiológico. $\mathrm{O}$ objetivo do construtivismo era satisfazer as necessidades materiais e expressar as aspirações, organizar e sistematizar os sentimentos do proletariado revolucionário. Entre os objetivos do construtivismo estava o de criar uma arte de significação utilitária e a produção era baseada em ciência e técnica, em lugar das atividades especulativas dos artistas antecedentes.

A partir dos anos 90 os artistas começam a trabalhar com mais liberdade de expressão, interligando com mais veemência a arte aos acontecimentos da vida e à tecnologia (criando/usando/interagindo os/com os aparatos tecnológicos). E, no século XXI como aponta Domingues (2003) essa proposta artística intensifica-se.

O período da década de 90 para o início do século $\mathrm{XX}$ foi de avanço nos pensamentos, estudos e reflexões sobre os processos tecnológicos. Sendo que no final do século XX e início do século XXI outras manifestações artísticas e novas formas de pensar a arte entrelaçada com as TIC foram surgindo. Entre essas novas manifestações conforme relata Domingues (2003, p. 97) estão a instalação, a performance, as multimídias artísticas, e mais recentemente as caves.

A arte acompanha o contexto-histórico social como também caminha ao encontro das necessidades criativas singulares a cada sujeito. Entre suas características principais está o entrelaçamento com a vida. E ainda a arte possibilita ao homem dá significados a acontecimentos que ocorrem dentro de si e ao que está à sua volta, sendo que a motivação humana de criar está inserida na busca de significados. O homem necessita de comunicar-se e relacionar-se - consigo mesmo e com outros entes -. E é com a comunicação e com a linguagem que o homem sempre relaciona e dá forma, seja ao agir, sonhar, imaginar. Garcia (2003. p. 58, grifos nosso) nos diz: “os trabalhos de arte são signos icônicos, demonstrando através de formas não verbais elou verbais, as vivências subjetivas do artista aliadas à concepção de mundo de uma época”.

As reflexões, desafios e possibilidades que apresentamos neste estudo sobre a criação, com o diálogo "Processos Tecnológicos, Educação e Arte", evidenciam a necessidade de se recriar uma atividade educativa do docente que funcione no decurso da vida. Atividade esta que, favoreça a formação contínua e prazerosa dos sujeitos - docentes e discentes -, pois, possibilita a participação de todos em sentido cooperativo; deixa fluir a interação acompanhada da alteração; desenvolve a autonomia com responsabilidade; implica a reflexão sobre o próprio percurso e sobre o contexto, 
com a, apresentação e criação de soluções diversas para melhorar a realidade vivida e a potencialização dos próprios sujeitos; experiencia a produção/criação de novos conhecimentos e de obras de artes; gera mudanças e transformações; e possibilita, sobretudo, a geração de sentidos e significados.

\title{
Educação de jovens e adultos na contemporaneidade: desafios e possibilidades
}

\begin{abstract}
A formação enraíza-se na articulação do espaço pessoal com o espaço socializado; progride com o sentido que a pessoa lhe dá, tanto no campo da sua experiência de aprendizagem com o formador, como no quadro da totalidade da sua experiência pessoal [...] A prática de formação é reforçada por uma prática de comunicação. Portanto, se o formador torna possível que o autor da formação seja também autor de um discurso sobre a sua formação, este último terá acesso, pela palavra (e por suas criações), ao sentido que dá à sua formação e, mais ainda a si própria.
\end{abstract}

(NÓVOA, 2010, p. 131-132, grifos nosso)

"[...] O conhecimento serve para a vida, não para a escola", esta convicção de Cunha (1998, p. 89) deve ser uma reflexão de todo educador. Tanto a citação de Nóvoa (2010) como a convicção de Cunha (1998) demonstra que os desafios e possibilidades da/na docência devem provir esta/nesta/desta questão: é na dinâmica do viver que os conhecimentos são constituídos. Não há, portanto, um conhecimento pronto, mas conhecimentos provisórios, passíveis sempre de alterações (CUNHA, 1998). E, esta é a essência mesma do conhecimento - a reelaboração -. A produção de conhecimentos deve, necessariamente, permitir ao sujeito ter consciência de si mesmo e de sua realidade, deve permitir a cada sujeito maneiras de interpretar esta sua realidade, expandindo-a, criando outras realidades, criando significados e sentidos.

Pensar, pois, numa EJA comprometida realmente com a aprendizagem efetiva dos jovens e adultos, repercute repensar nas questões do currículo, da metodologia, e da formação. Vale lembrar as palavras de Moacir Gadotti (2008, p. 27): “[...] os jovens e adultos alfabetizados já foram desrespeitados uma vez quando teve seu direito a educação negada". Não podem agora, ao retornar sua instrução, serem humilhados mais uma vez por uma metodologia que lhes nega o direito de afirmação de sua identidade, de seu saber, de sua cultura. Tânia Dantas (2012, p. 159), em seus estudos, também constatou:

Como campo epistemológico, a Educação de jovens e Adultos é marginalizada ou colocada em segundo plano no currículo dos cursos de pedagogia e nas licenciaturas de formação de professores para as diversas áreas do conhecimento, provocando uma importante lacuna na formação inicial dos professores que poderão atuar (às vezes já atuam) na modalidade da EJA. 
Sendo que há, portanto, uma necessidade de que a formação de profissionais para atuar na modalidade de ensino de Jovens e Adultos, como ressalta Dantas (2012, p. 153) atente para “[...] a diversidade desta clientela formada por jovens e adultos com diversos interesses, observando suas demandas peculiaridades, diferenças culturais, experiências de vida, percursos históricos, saberes, características específicas considerando-os como sujeitos históricos e atores sociais”.

Cunha (1998), em seu estudo, ressalta que a perspectiva do ensino como produção de conhecimentos, em nível de currículo, deve pois, partir da prática e/ou da leitura da realidade o próprio contexto vivencial, configurar a dúvida intelectual e, a partir desta, adentrar no conhecimento teórico. Ainda de acordo com Cunha (1998, p. 70), “[...] a prática é sempre multidisciplinar porque assim é a dinâmica da vida”. Essa prática ou realidade vivida, portanto, citada por Cunha (1998) é o elemento principal movedor/motivador da teoria. E, é a partir da reflexão sobre essa prática vivenciada que os alunos poderão criar, produzir conhecimento, resolver problemas, construir uma nova realidade que atenda aos seus anseios e aos do seu grupo.

Desse modo, o ensino desenvolvido no âmbito do paradigma emergente, coloca o conhecimento como algo constituído por cada pessoa imergida em seu contexto vivencial subjetivo -, e no diálogo com os outros em sentido de interação/cooperação - coletivo -. O conhecimento é, portanto, constituído subjetiva e coletivamente e está em constante multiplicidade, ou seja, promovendo sempre o desenvolvimento. Cunha (1998, p. 10) aponta: "todo o conhecimento é uma produção social, isto é, nasceu num espaço e num tempo em função dos desafios sóciocognitivos de um contexto". Desse modo, o docente, assim como seus alunos tem essencial papel nesta dinâmica emergente, pois, participam juntos, construindo uma nova forma de ensinar e aprender.

O paradigma emergente insere os alunos na condição de não apenas protagonistas, mas, de co-autores, participantes ativos e instituidores de novas realidades. Esses alunos ampliam e constroem conteúdos associados à própria realidade vivida, e por isso mesmo trabalham com prazer. O docente imerso nesse paradigma da educação contemporânea aporta-se para algo que é essencial: possibilitar que os sujeitos estejam cientes de seus próprios processos de pensamento. Portanto, esta nova forma de lidar com o conhecimento, permite que cada sujeito possa refletir sobre si, sobre como realiza seus trabalhos e, de que forma sua atuação pode ser melhorada e melhorar os contextos vivenciais.

Ressaltamos, pois, que a relevância que damos aos conhecimentos, experiencias e historicidade de cada estudante da EJA possibilita a valorização de suas singularidades, especificidades e do conhecimento de vida de cada um. Assim, tendo em conta que o processo de 
construção do conhecimento se constitui aliando conhecimentos prévios, contato com a realidade circundante, bem como novos conhecimentos, este pressuposto torna-se indispensável na promoção do conhecimento na EJA. Como bem ressalta Barcelos (2010, p.50) “[...] não existe separação entre aquilo que as epistemologias tradicionais chamam de dimensão biológica e dimensão cultural da pessoa, e, consequentemente, nos seus processos de viver". Ainda para este pesquisador: “dentre esses processos se situam a produção de conhecimentos e, como não poderia deixar de ser, a aprendizagem de homens e mulheres no e com o mundo". O importante, ainda pensando com Barcelos, é estarmos sempre atentos e vigilantes no sentido de nunca fechar os espaços para a imaginação e para a criação.

As discussões acima suscitadas apontam o aluno da EJA como um sujeito criativo, que possui aspirações ideológicas diferentes dos alunos do ensino regular. Para o aluno, sobretudo da EJA, o espaço da escola deve ser de crescimento pessoal, de valorização de suas experiências e de suas vivencias. Para Barcelos (2010) a escola é um dos territórios de experiências humana sensível. Um lugar de palavras, de gestos, de silêncios e de atitudes. Um território de experiências vivas e vividas. Lugar onde conhecimentos e saberes se encontram, se confrontam, se antropofagiam ou se anulam.

Entender, portanto, a escola como um espaço de formação dos sujeitos da EJA, torna-se fundamental o desenvolvimento social, criativo, crítico e emocional destes jovens e adultos estão totalmente implicados neste processo de formação. A escola neste sentido, como bem afirma Gadotti (2003, p. 171) é “[...] um espaço político, limitado, mas de importância relativa na superação das contradições da sociedade". Subtendemos desse modo, que a escola é um espaço biográfico de criação - de si, de conhecimentos e de obras de arte - tomando, pois, estas criações como obras da vida.

A pesquisadora Dantas (2012, p. 152) ressalta que os jovens e adultos são sujeitos da aprendizagem. Sendo que o trabalho educativo desenvolvido com estes deve estimular o exercício da criticidade, a promoção da curiosidade, a valorização dos aspectos emocionais, a afetividade, os sentimentos, a sensibilidade e de suas histórias de vida. Pois, tudo isto está implicado na formação, ou seja, no ato de formar e formar-se.

Assim, docência desenvolvida no paradigma emergente coloca ensino- pesquisa-extensão como acontecimentos indissociáveis, permite ainda avançar os conhecimentos inerentes a cada sujeito atrelando-os com os novos conhecimentos desenvolvidos. Brunner (2001, p. 72) acrescenta: “os alunos devem, no final das contas, utilizar sua própria inteligência e sua própria motivação para extrair algum benefício do que a escola tem a oferecer. A educação é um meio para fortalecer e 
capacitar nossos poderes mentais inatos". Cunha (1998, p. 67) intensifica: “entende-se conhecimento aqui para além das informações, como modos de pensar, de ver, de sentir e de atuar no mundo".

\title{
Docência e arte: reflexões, registros e criações em processos criativos - percurso do sujeito
}

\begin{abstract}
O processo de reflexão caracteriza-se pelo uso da capacidade de abstração face à descrição casuística, a fim de compreender o que foi estruturante e mobilizador para o sujeito. A singularidade de cada percurso serve para ilustrar, por intermédio de uma configuração particular, uma ideia geral que deve dar a cada participante uma compreensão suplementar e enriquecer as significações anteriormente atribuídas, assumindo-se simultaneamente como um momento do próprio processo.
\end{abstract}

(NÓVOA, 2010, p. 73)

Quando o docente possibilita uma atividade educativa desenvolvida na indissociabilidade entre ensino-pesquisa-extensão (CUNHA,1998) permite que cada sujeito reflita sobre seu próprio percurso e busque novas compreensões e interpretações, a criação de novos conhecimentos e obras de arte, alterações necessárias para gerar melhorias para a sua realidade vivida e, a elaboração consciente, crítica e criativa de outras realidades. Este processo, pois, de produção de conhecimento ou mesmo de educação implica um processo de criação artística e, nesta base, epistemologia e estética assumem fronteiras porosas, flexíveis e não rígidas e isoladas, já que é no percurso do sujeito que se manifestam as criações, os registros e as reflexões em processos criativos abertos, revelando a própria formação contínua do sujeito.

Nesta reflexão sobre a docência em sua relação com a Arte, destacamos a necessidade de entender o que são de fato os processos criativos e, refletir sobre as possibilidades da Arte, sobre o significado de criatividade, de criação, de currículo e de potencial criador. O entendimento sobre essas essências certamente possibilitará uma compreensão maior quanto às contribuições da Arte para a Docência, para a atividade educativa e para a criação.

\section{Percurso do Sujeito}

Neste cenário da transição de paradigmas, Cunha apresenta que:

As experiências de vida e o ambiente sócio cultural são componentes-chave na explicação do desempenho atual do professor, quer na categoria da reprodução quer na da contradição. O conjunto de valores e crenças que dão escopo à performance dos docentes são frutos de sua história e suas experiências de vida dão contornos ao seu desempenho.

(CUNHA, 1998, p. 53) 
O contexto contemporâneo da educação evidencia que o docente, na relação com seu aluno, ao mesmo tempo em que se implica, indicando e construindo juntos caminhos, libera-se do autoritarismo, pois deixa o seu aluno livre para desenvolver sua autonomia (CUNHA, 1998), aprofundar em conteúdos e criar conhecimentos conforme suas próprias possibilidades. Desse modo, então, o docente trabalha com e permite o acontecer, pois, em sua práxis combinam duas premissas responsabilidade e liberdade, indispensáveis no processo criativo do qual tanto o aluno como o professor participa. Lima Jr. (2005, p. 203) apresenta que o currículo gerado nesses termos configura "a possibilidade constante de se criar os próprios caminhos, configurando-os no próprio caminhar, como base na multiplicidade de interesses, demandas e necessidades, criando-se ao mesmo tempo possibilidades de convivência de diferentes caminhos e tipos de relações entre eles".

Essa dinâmica, portanto, do saber emergente insere, desde já, o aluno na condição de pesquisador (CUNHA, 1998, p. 84) em estado constante de formação, sendo que seus percursos individuais e a interação sócio-histórica-cultural estão totalmente implicados. Nóvoa (2010, p. 172, grifos nosso) atesta que "[...] a formação contínua deve ser entendida como uma contribuição exterior que pode modificar certas trajetórias de vida pelas quais as pessoas se constroem pouco a pouco". E mais ainda, “a formação pertence exclusivamente à pessoa que se forma" (p. 172), todavia,

É evidente que todo mundo depende dos apoios exteriores que ajudam, estimulam e inspiram os percursos individuais: a formação é um espaço de socialização e está marcada pelos contextos institucionais, profissionais, socioculturais e econômicos, em cada indivíduo vive. Por outro lado, a história individual está em interação constante com os acontecimentos históricos que modelam o futuro de uma dada sociedade. Mas não deve desvalorizar o fato de que pertence exclusivamente ao adulto fazer a síntese do conjunto das influências exteriores e apropriar-se do seu próprio processo de formação (NÓVOA, 2010, p. 172-173).

Ainda, corroborando as palavras de Nóvoa, Cunha (1998, p. 35) relata: "o valor que os professores dão à prática docente enquanto a sua grande inspiração para a mudança e ao saber que constroem a partir daí", sendo que "nela localizam a possibilidade de aprenderem com colegas de trabalho, com alunos e de, refletindo sobre a própria docência, reformularem sua forma de pensar e agir” (idem, p. 35). Neste caso, ainda de acordo com Cunha (1998, p. 35), “[...] há a confirmação de que o indivíduo vive é insubstituível no seu significado educativo. O fazer e o refletir sobre este fazer têm sido, no dizer dos bons professores, um mecanismo fundamental para delinearem seu desempenho docente".

O que fica explícito, portanto, é que na composição de currículos e na constituição de conhecimentos neste contexto contemporâneo emergente não predomina o império, mas a 
equivalência e convivialidade dos saberes e dos sujeitos diferentes, ou seja, cada saber e cada sujeito é em si mesmo - tem a sua essência e singularidade -, mas, dialoga, combina, "transita" entre/com os outros diferentes, e neste diálogo amplia-se continuamente, como um processo que está sempre em composição e configuração. Entender isso é fundamental para promover o desenvolvimento. Aqui vale lembrar também as palavras de Lima Jr. (2005, p. 203).

É preciso entender e explicitar a configuração ou a composição curricular, não mais sua estruturação. Isso não através de uma megaconfiguração multirreferencial, mas da convivência e coexistência de configurações curriculares diferentes, cada qual sendo uma singularidade com sentido, emergente e negociada no contexto mais amplo da interminável busca do Homem pela compreensão do mundo, interior e exterior a si, num processo plural de produção de conhecimento e de constituição de si e do mundo, isto é, da realidade, da qual é parte integrante e integra, portanto, tratando-se de singularidades criadas, transitórias, abertas e inacabadas.

É necessário, portanto, perceber que o conhecimento, as produções, e a própria constituição dos sujeitos faz-se na relação, e só fazem sentido se não forem analisadas separadamente, mas na relação, como enfatiza Cunha (1998). Então, o docente ao possibilitar o diálogo, a transformação e a criação, permite que os sujeitos envolvidos - professores e alunos transformem dificuldades em oportunidades, alternativas e criações. Cunha ressalta que "[...] o conhecimento é processo, portanto não é absoluto nem acabado. É elemento para ser superado" (CUNHA, 1998, p. 88). E, “aprender é aprender a criar e o que faz da aprendizagem algo criativo é a pesquisa. A verdadeira aprendizagem é aquela construída com esforço próprio através de elaboração pessoal" (p. 88).

Neste sentido, podemos dizer que a produção de conhecimento e a própria composição do currículo dos sujeitos é um processo criativo, que se constitui continuamente na própria dinâmica do viver. Por isso, como destaca Cunha (1998) a essencialidade de o professor perceber que a concepção do conhecimento envolve flexibilidade e movimento e, além disso, constatar que existem diferentes fontes e formas de elaboração e a essência do conhecimento é a produção/criação com reflexão e ação.

\section{Processos criativos e quando eles acontecem}

Compreendemos, na criação, que a ulterior finalidade de nosso fazer seja poder ampliar em nós a experiência de vitalidade. Criar não representa um relaxamento ou um esvaziamento pessoal, nem uma substituição imaginativa da realidade; criar representa uma intensificação do viver, um vivenciar no fazer; e, em vez de substituir a realidade, é a realidade; é uma realidade nova que adquire dimensões novas pelo fato de nos 
articularmos, em nós e perante nós mesmos, em níveis de consciência mais elevados e mais complexos.

(OSTROWER, 1987, p. 28)

O paradigma emergente sugere, essencialmente, que os professores possibilitem que seus alunos estejam cientes de seus próprios processos criativos e de como eles são constituídos, percebendo que estes processos são configurados na/com a própria formação, ou são em si o estado de formação dos sujeitos, portanto são complexos e dinâmicos. Os processos criativos são os modos de instituir, constituir, produzir e criar dos sujeitos.

Estes processos, como ressalva Lima Jr. (2005, p. 102), são constituídos/constituem e acontecem no/com o dinamismo da vida e da realidade, no qual "[...] o ser humano participa do dinamismo criativo da vida e da realidade e, de dentro dela, reflete sobre tal processo, percebendo-o e percebendo a si mesmo nele, representando-o comunicando entre si ao nível mental e da linguagem". Nesses processos, pensando com Lima Jr. (2005, p. 103, grifos nosso) há “[...] emergências, composições, configurações, singularizações e criações são eventos concretos, vivíveis e ao mesmo tempo flexíveis, dinâmicos, abertos, em fluxo e em devir”. Os processos criativos desse modo podem ser entendidos como "[...] espaços acontecimentais" (LIMA JR., 2005, p. 99). Estes acontecem nas/com diversificadas possibilidades de criação.

\title{
Possibilidades da Arte e a produção de conhecimentos
}

\begin{abstract}
O conhecimento pós-moderno é um conhecimento sobre as condições de possibilidade incentivado a emigrar para outros lugares cognitivos e postos sobre as condições de possibilidades da ação humana projetada no mundo a partir de um espaço - tempo local. Isto significa que ele nunca é absoluto e contém sempre a ideia de movimento, além de ser entendido como teia que se relaciona e se ramifica.
\end{abstract}

(CUNHA, 1998, p. 68)

As possibilidades da Arte são infinitas e se revelam no próprio criar do sujeito. E as possibilidades criativas como relata Ostrower (1987, p. 187) existem em todas as áreas do fazer humano, não apenas no fazer artístico. Lowenfeld e Britton (1977, p. 50, grifos nossos) também ressaltam que "[...] a arte proporciona aos sujeitos uma vasta gama de possibilidades [...] As respostas que eles procuram e as soluções que descobre são suas, e o desenho, a pintura ou a construção que executa refletem sua crescente capacidade para lidar com uma série diversificada de possibilidades”. Para Zamboni (2006, p. 21): “[...] a atividade do pensamento permeia todo e qualquer tipo de conhecimento humano" e mais ainda "[...] a arte pode constituir-se num importante veículo para outros tipos de conhecimento humano, já que extraímos dela uma compreensão da experiência humana e dos seus valores" (p. 22). 
O paradigma da educação emergente coloca isso em evidência - deixar as pessoas compreenderem que nos mais diversos níveis de experiência de vida, de relacionamentos, e de criação elas podem trabalhar e trabalham com a criatividade. Cunha ressalta: "[...] a forma como os professores encaminham suas propostas de trabalho, estimulando a participação dos alunos, faziam (fazem) da aula espaço para criação de dúvidas, leituras e interpretações de textos, trabalho em grupo, poesias, mídias, observações, vídeos” (CUNHA, 1998, p. 88, grifos nossos). A produção de conhecimentos assim como a criação de obras de arte, portanto, faz-se num processo criativo gerado em, e gerando relações que se potencializam.

\section{O que significa criação?}

Ostrower nos diz que criar é basicamente dar forma (OSTROWER, 1978, p. 9). Ao criar o homem participa conscientemente da vida e busca o novo. Sendo que os valores culturais, sociais e políticos influenciam as configurações do sujeito. Esses mesmos valores culturais, políticos e sociais já determinam antes alguns significados. Ostrower $(1978$, p. 9) diz que tanto o fazer quanto o configurar do homem são atuações de caráter simbólico, pois este busca dá significados a acontecimentos que ocorrem dentro de si e ao que está à sua volta. A autora (1978) aponta ainda que a criação é decorrente da necessidade que o homem tem de comunicar-se com outros seres humanos (nós acrescentamos, e com outros entes não-humanos já imbricados com o humano). Ainda com Ostrower (idem) essa comunicação se dá através de formas. O homem sempre relaciona e dá forma, seja ao agir, sonhar, imaginar. Quanto à forma Garcia (2003, p. 65) diz que esta “[...] é a expressão exterior do conteúdo interior”.

Manifestar-se artisticamente é dar forma a algo. O homem se movimenta entre formas. Toda forma é concomitantemente forma de realização e forma de comunicação. O homem é um ser formador antes mesmo do ato de fazer. A forma reflete os processos de crescimento e maturidade, tão característicos do ato de criar. Esse, "dar forma" de acordo a perspectiva epistemológica hipertextual/proposicional suscita sempre um devir, ou seja, a forma criada é flexível, dinâmica, passível a ressignificações/composições/configurações (LIMA JR., 2005, p. 95). Citando May (1975. p. 136-137): “a paixão pela forma significa um princípio da expressão humana (...) essa paixão pela forma é uma tentativa de dar sentido à vida". Ainda de acordo com este (MAY, 1975) o processo de maturidade é responsável pela espontaneidade e liberdade no criar.

A criação de conhecimento como um ato artístico compõe-se a partir da capacidade criativa do sujeito, como também de um fazer, de uma construção, de uma produção, de um processo. Refletindo com Bosi (2000, p. 13, grifos nosso) temos que “[...] a arte é um conjunto de 
atos pelos quais se muda a forma, se transforma a matéria oferecida pela natureza e pela cultura. Nesse sentido, qualquer atividade humana, desde que conduzida regularmente a um fim em 'metamorfose', pode chamar-se de artística”. E mais ainda: “[...] a arte é uma produção; logo supõe trabalho. Movimento que arranca o ser do não ser, a forma do amorfo, o ato da potência, o cosmos do caos" (BOSI, 2000, p. 13). Subtendemos desse modo, que a arte, enquanto processo criativo possibilita que aos sujeitos criar conhecimentos e obras de arte - a obras de vida.

\section{O que significa criatividade e quem trabalha com ela?}

[...] a criatividade, como a entendemos, implica uma força crescente, ela se reabastece nos próprios processos dos quais se realiza.

(OSTROWER, 1987, p. 10-25).

A partir desta citação de Ostrower podemos dizer que a criatividade é a própria capacidade do sujeito de elaborar e de (re) elaborar-se. É algo, portanto, que é inerente a todos os homens, todos podem trabalhar com a criatividade. A criatividade envolve a produtividade dos sujeitos, a vontade de encontrar significados, a motivação. Cunha intensifica que a criatividade é essência da pesquisa e da aprendizagem, “[...] o que faz da aprendizagem algo criativo é a pesquisa” (CUNHA, 1998, p. 88). Lima Jr. (2005) evidencia, pois, que ao criar o próprio sujeito já está implicado em sua criação, e essa relação se dá de maneira complexa, sendo que o sujeito criativo se faz dentro do seu contexto vivencial:

[...] a implicação refere-se à participação do sujeito no ato do conhecimento, fazendo com que a questão da lógica e a questão epistemológica em geral saiam do âmbito do idealismo e retornem ao âmbito da vida e dos contextos humanos, ao âmbito do social, do individual e, especialmente, ao âmbito da criatividade (LIMA JR., 2005, p 159-160).

Sendo assim, portanto, a criatividade permite que cada sujeito (artistas ou não) elabore possibilidades, e amplie suas potencialidades humanas imbricadas com a teckné ou seja, - suas potencialidades humanas tecnológicas -.

\section{O que é o potencial criador e em quais sujeitos se manifesta?}

O potencial criador é uma experiência vital, criar é tornar o viver mais intenso, o artista se vivencia no fazer.

(OSTROWER, 1987, p. 31).

Digamos com Ostrower (1987, p. 10) “[...] o potencial criador do homem surge na histórica como um fator de realização e constante transformação. Ele afeta o mundo físico, a própria condição humana e os contextos culturais". O potencial criador, portanto, se manifesta em todos os 
sujeitos e coloca em evidência o agir sensível e consciente desses sujeitos. É no potencial criador que se revela a ação humana de criar, de fazer, de instituir. É por meio deste potencial que surgem as novas alternativas. Esse potencial criador elabora-se no sujeito, e como afirma Ostrower (1987, p. 27): "se faz presente nos múltiplos caminhos em que o sujeito procura captar e configurar as realidades da vida".

Para Dominicé (2010, p. 95) os conhecimentos adquiridos pelos adultos resultam de uma rede de fontes de informação. Sendo que: "o saber de referência está, sobretudo relacionado com a maneira como os adultos voltam a trabalhar ou modificam o que os agentes da sua educação quiserem ensinar-lhes". A formação, neste sentido, depende do que cada um faz do que os outros quiseram, ou não quiseram, fazer dele. Ainda pensando com Dominicé (2010, p. 95) “[...] a formação corresponde a um processo global de autonomização, no decurso do qual a forma que damos à nossa vida se assemelha ao que alguns chamam de identidade”.

Também quanto à formação, em seu estudo sobre atos de currículo, Macedo (2013, p.53) afirma: "ao avaliar a formação como um ato de currículo é fundamental a contextualização das circunstâncias com as quais a aprendizagem acontece", ainda, "a formação se realiza num laboratório a céu aberto. Nesses termos, as circunstâncias fazem parte do próprio ato de avaliar, porque a aprendizagem reflete essa realidade".

Para este pesquisador (MACEDO, 2013, p. 53) “[...] quem aprende e compreende é o sujeito, sempre em relação, mas é o único que ao final pode demonstrar a sua condição de estar em formação ou formando-se, com todas as ambivalências que podemos viver nessas experiências". Isso porque a formação na sua base semântica mais elaborada quer dizer modo de ser. Em correlação com este pensamento Fulanetto (2010, p.170) ressalta: “a formação não é algo que acontece em paralelo a vida, mais que se articula a ela". Sendo que: "ao retornar sua história de vida nos espaços de formação, e ao pensar sobre ela, os sujeitos se reencontram com experiências simbólicas que se apresentam como ideias, emoções, acontecimentos que se destacam do pano de fundo da existência e pedem para serem compreendidos". Ainda para esta pesquisadora (2010, p. 170): "o adulto, ao entrar em contato com seu percurso, pode buscar, de certa forma, em sua vida, em suas experiências tomar consciência de um plano que vem permeando suas ações. Ao retornar sua história de vida, percebe que elas se articulam, desenhando um plano nem sempre conhecido".

A formação, ainda pensando com Fulanetto (2010, p. 170), expande seus limites. Pois, “[...] ao acolher os conteúdos 'não sabidos' possibilita que a consciência, também, se expanda na vivência desse processo. Dessa forma estará o adulto mais equipado". Neste sentido, ao valorizar os espaços biográficos, enquanto espaço também de formação, de criação de conhecimentos e, de 
obras de arte, cria-se a possibilidade de que cada jovem e adulto - sujeito criativo - promova intervenções no mundo, desenvolva experiências respeitosas de liberdade, e como diria Freire (1996, p. 107) desenvolva “[...] a autonomia, enquanto amadurecimento do ser para si, é processo, é vir a ser".

Fica explícito, portanto, a idéia de que a atividade educativa instituinte na contemporaneidade com o saber emergente coloca em evidência o próprio percurso dos sujeitos estando sempre em processos criativos, revelado em e revelando registros, reflexões e criações de cada sujeito implicados em sua formação. Sendo que suas potencialidades são geradas singularmente como também nas relações entre os sujeitos. E, a criatividade e o potencial criador em cada um possibilitam a constituição contínua e dinâmica de conhecimentos.

\section{A importância da arte na educação de jovens e adultos}

Os dados apresentados neste tópico são resultantes da observação em sala de aula e da realização de um questionário desenvolvidos junto a duas escolas da rede pública estadual de ensino em Salvador, como parte da pesquisa de Mestrado em Educação de Jovens e Adultos. Os sujeitos da pesquisa foram 30 estudantes e 2 professoras da Educação de Jovens e Adultos. A maioria destes estudantes, oriundos de comunidades vulneráveis socialmente, apresenta idade entre 20 e 65 anos, e as professoras envolvidas entre 40 e 50.

Os estudantes da EJA, como explica Ventura (2012, p.74): "são oriundos das frações mais empobrecidas da classe trabalhadora, submetidos a precárias condições de produção da existência, historicamente destituídas dos direitos humanos essenciais". Ou seja, a EJA engloba geralmente estudantes desassistidos socialmente e que voltam à escola tentando encontrar nesta, subsídios que lhe proporcione maiores condições de bem viver, seja no mundo do trabalho, seja no mundo da cultura.

Nossa observação mostrou que pensar em arte na Educação de Jovens e Adultos implica pensar em possibilidades de gerar ações criativas e transformar o próprio contexto sócio-históricocultural em que vive. Conduta esta que envolve a própria existência, a cultura, a geração de novos sentidos e possibilidades de transformação da realidade.

Durante a pesquisa cada estudante respondeu a um questionário contendo dez perguntas. Com este procuramos conhecer a compreensão que o estudante da EJA tem a respeito da importância da Arte como componente curricular. Dentre as configurações apresentadas destacamos algumas apresentadas para o conceito de criação e da importância da inserção da Arte no currículo da EJA. Observemos nos Quadros 2 e 3: 
Quadro 2 - O que significa criação?

CONFIGURAÇÃO

Deixar a imaginação fluir...

É a capacidade que temos de elaborar uma composição artística.

Desenvolvimento e criação.

Criação para mim significa saber elaborar as coisas.

Criar algo, experimentar; desenvolver a mente criando algum projeto.

É poder expressar um talento de saber formar algo.
PAICIPANTE

Prof. Lic. Educação Artística

Prof. Lic. História

Estudante, ESPGMN

Estudante, ESPGMN

Estudante, CEAS

Estudante, CEAS

Fonte: Elaborado pela autora, 2015.

O questionário possibilitou uma aproximação do estudante com os objetivos do ensino e estudo da Arte na Educação de Jovens e Adultos. A maioria dos estudantes demonstrou satisfação em participar da pesquisa. As professoras das turmas também participaram e responderam ao questionário contendo 10 questões relacionadas à importância da Arte na construção do conhecimento na Educação de Jovens e Adultos.

QUADRO 3 - Importância da Arte no currículo da EJA.

\section{CONFIGURAÇÃO}

\section{PARTICIPANTE}

Prof. Lic. Educação Artística

É fundamental. Não podemos fazer pensar, sem primeiro fazer sonhar.

Entendemos que a Arte preenche uma lacuna que estimula a

Prof. Lic. História

criatividade e possibilita outras leituras de mundo.

Facilita mais para que todos tanto conheça as artes e atividades

Estudante, ESPGMN

laborais como as artes. 
Estudante, ESPGMN

É uma matéria incluída para que nós alunos possamos ter lá na frente um bom currículo e um desempenho lá na frente.

É importante para o desenvolvimento e conhecimento do aluno.

Estudante, CEAS

É fundamental, pois aprendemos mais da cultura e das artes do

Estudante, CEAS nosso país e de outros.

Fonte: Elaborado pela autora, 2015

Nesse ensejo destacamos que ao possibilitar que cada educando reflita sobre seu contexto o professor permite que estes criem e repensem o seu ambiente, e aperfeiçoe suas próprias técnicas de criação. Neste processo de criação inclui-se uma reflexão a respeito da existência, da figura humana: homens e mulheres; jovens, adultos, idosos voltam-se para suas próprias experiências.

$\mathrm{O}$ ato de criar, predominante nas aulas de Arte da EJA coloca a criação no cerne da ação curricular, havendo, neste sentido, no próprio ato pedagógico abertura para não apenas expressão, mais incluindo aí interpretação, reflexão e ação realizada pelo professor e pelo educando que dá sentido à sua expressão que pode ser estética, artística, tecnológica ou epistemológica. O professor de arte da EJA que coloca isso em evidência deixa que seus educandos compreendam que nos mais diversos níveis de experiência de vida, de relacionamentos, e de criação podem trabalhar com interpretação e geração de significados.

Tais dados obtidos através da observação e dos questionários evidenciam a necessidade de que a escola seja cada vez mais repensada como um dos lugares sociais em que ocorre o desenvolvimento cognitivo, inclusive através da criatividade, bem como a apropriação de saberes visando sempre à elevação dos sujeitos a partir de uma proposta de formação bem estruturada e equilibrada. Portanto, pressupõe-se que neste lugar durante sua trajetória de escolarização, os estudantes desenvolvam suas capacidades intelectuais, que se tornem sujeitos autônomos e críticos e, que aprendam a socializar-se de maneira ética e afetiva. Nas escolas estaduais onde tecemos a pesquisa desenvolve-se atividades e projetos visando alcançar esta meta.

\section{Considerações Finais}

As criações, pois, constituem-se continuamente a partir das relações histórico-social e possuem caráter contextual. E, por isso mesmo, essas criações também provêm da relação do sujeito com suas experiências, com sua dinâmica interna e com a própria dinâmica do viver. Cada ser humano forma-se num contexto de diálogo, transformação e criação. Desse modo, nesta pesquisa, 
consideramos cada estudante da Educação de Jovens e Adultos, sujeito criativo, que cria revelando sua inteligibilidade.

Evidencia-se neste estudo, portanto, que as criações acontecem tendo nas relações um manancial, na qual cada sujeito tem a possibilidade de experienciar, criar, criar-se e ao mesmo tempo ampliar potencialidades. Assim, as reflexões aqui apresentadas propõem novas provocações, críticas e novos processos de humanização e a geração de novas possibilidades educativas.

\section{Referências}

ANSELMO, Rener. A Linha da Formatividade na Bahia. Cultura Visual. Revista do Mestrado em Artes Visuais da Escola de Belas Artes, Salvador, v. 1, n, 5. $2^{\circ}$ Semestre. 2003. p. 104-114.

BARCELOS, Valdo. Educação de Jovens e Adultos: currículo e práticas pedagógicas. Petrópolis, RJ: Vozes. 2010

BOSI, Alfredo. Reflexões sobre a arte. São Paulo: Ática, 2000

BRUNER, Jerome. A cultura da educação. Porto Alegre: Artmed, 2001

CUNHA, Maria Isabel. O professor universitário na transição de paradigmas. Araraquara: JM, 1998.

DANTAS, Tania Regina. Formação de professores em EJA: uma experiencia pioneira na Bahia. Revista da FAEEBA. Educação e Contemporaneidade, Salvador, v. 21, n. 37, p. 147-162, jan./jun. 2012.

DOMINICÉ, Pierre. O processo de formação e alguns dos seus componentes relacionais. In: NÓVOA, A.; FINGER, M. (Org.). O método (auto) biográfico e a formação. Natal: RN EDUFRN. São Paulo: Paulus, 2010. p. 80-95.

DOMINGUES, Diana. Arte e vida no século XXI: tecnologia, ciência e criatividade. São Paulo: Ed. UNEB, 2003.

FREIRE, P.; MACEDO, D. Alfabetização: leitura da palavra leitura do mundo. Tradução L. L. de Oliveira. Rio de Janeiro: Paz e terra, 1990.

FREIRE, Paulo. Pedagogia da autonomia: saberes necessários a prática educativa. São Paulo: Paz e Terra. 1996

FURLANETTO, E. C. "Individualização historia de vida e formação". In: BARBOSA, R. L. L.; PINAZZA, M. A. (Org.). Modos de narrar a vida: cinema, fotografia, literatura e educação. São Paulo: Cultura acadêmica. 2010

GADOTTI, Moacir. MOVA, por um Brasil Alfabetizado. São Paulo: Instituto Paulo Freire. 2008 Concepção dialética da educação: um estudo introdutório. São Paulo: Cortez. 2003. 
GARCIA, Roseli Amado da Silva. Em busca da essência: um pensamento plástico filosófico. Salvador: Editora da Faculdade Integrada da Bahia. FBI, 2003.

A produção artística e sua relação com as descobertas tecnológicas: uma breve apreciação. In: Norma Correa. (Org.). Artes visuais na Bahia. 1 ed. Salvador. J.J. Randam. 2003. p. 71-76.

LIMA JUNIOR, Arnaud Soares de. Tecnologias intelectuais e educação: explicitando o princípio proposicional/hipertextual como metáfora para educação e o currículo. Revista da FAEEBA Educação e Contemporaneidade, Salvador, v. 13, n. 22, p. 401-416, jul./dez. 2004.

. Tecnologias inteligentes e educação: currículo hipertextual. Rio de Janeiro: Quartet; Juazeiro, Bahia: FUNDESF, 2005. 2009. p. 4-53.

Educação e contemporaneidade: processos e metamorfoses. Rio de Janeiro: Quartet,

LOWENFELD, V.; BRITTON, W. L. Desenvolvimento da capacidade criadora. São Paulo: Mestre Jou. 1977.

MACEDO, Roberto Sidnei. Atos de currículo e autonomia pedagógica: o socioconstrucivismo curricular em perspectiva. Petrópolis, RJ: Vozes. 2013.

MAY, Rollo. A coragem de criar. Tradução Aulyde Soares Rodrigues. Rio de Janeiro: Nova Fronteira. 1975.

NÓVOA, Antonio; FINGER, Mattias. O método (auto) biográfico e a formação. Rio Grande do Norte: Ed. UFRN; São Paulo: Paulus, 2010.

OSTROWER, Fayga. Criatividade e processos de criação. Petrópoles: Vozes, 1987.

Acasos e criação artística. Rio de Janeiro: Campos, 1990.

PEREIRA, R. C. B.; PEREIRA, R. de O. A questão da docência no ensino superior. Juiz de Fora: Centro de Pesquisas Estratégicas Paulino Soares de Sousa. UFJF

STANGOS, Nikos. Conceitos de arte moderna. Rio de Janeiro. Jorge Zahar, 1991.

UCKER, Lílian; MARTINS, Raimundo. Escola: espaço/lugar onde os cotidianos são e estão sendo praticados. Goiânia: ANPAP, 2005. p. 430-440. 2 v.

VENTURA, Jaqueline. A EJA e os desafios da formação docente nas licenciaturas. Revista da FAEEBA. Educação e Contemporaneidade. Salvador, v. 21, n. 37, p. 71-82, jan./jun. 2012.

ZAMBONI, Silvio. A pesquisa em arte: um paralelo entre arte e ciência. Silvio Zamboni. 3. ed. São Paulo: Autores associados. 2006. 